\title{
COA Based SSSC and STATCOM Optimal Controllers Designing with The Aim of Better Damping of Oscillations: A Comparative Study
}

\author{
Behrouz Mohammadzadeh $^{1}$, Reza Gholizadeh-Roshanagh ${ }^{2}$, Sajad Najafi-Ravadanegh $^{2}$ \\ and Seyed Reza Seyed Nouri ${ }^{1}$ \\ ${ }^{1}$ Young Researchers and Elite Club, Germi Branch, Islamic Azad University, Germi, Iran \\ ${ }^{2}$ Smart Distribution Grid Research Lab, Department of Electrical Engineering, \\ Azarbaijan Shahid Madani University, Tabriz, Iran
}

\begin{abstract}
In this paper, the designing problem of two flexible $\mathrm{AC}$ transmission systems (FACTS)-based stabilizers are formulated for a cuckoo optimization algorithm (COA) with an objective function that includes the damping factor and the damping ratio of oscillations. This new optimization algorithm has a strong ability to find the most optimistic results for dynamic stability improvement. Also, its performance in 20 times run is the same as in 1 time run. Single machine infinite bus (SMIB) system has been considered to examine the operation of proposed COA based static synchronous series compensator (SSSC) and static synchronous compensator (STATCOM) controllers. Sudden change in the input power of generator is considered as a disturbance. The effectiveness of the proposed COA based SSSC and STATCOM controller for damping of low frequency oscillations is tested on a weakly connected power system with a disturbance and different loading conditions and their results are compared with each other. The eigenvalue analysis and time domain simulation results are presented to show the effectiveness of these FACTS-based stabilizers. The results obtained revealed the effectiveness of SSSC in comparison with STATCOM in damping power system oscillation and the results confirmed the effectiveness of the COA method for controller parameter optimization.
\end{abstract}

Keywords: SSSC, STATCOM, cuckoo optimization algorithm, low frequency oscillations damping

\section{Introduction}

As power systems became interconnected, areas of generation were found to be prone to electromechanical oscillations. These oscillations have been observed in many power systems worldwide [1]. Typical range of these oscillations is in the range of $0.2-3.0 \mathrm{~Hz}$. If these low frequency oscillations are not well damped, these may keep growing in magnitude until loss of synchronism results [1-3]. Power system stabilizer (PSS) is possibly the first measure that has been used to improve damping of oscillations. PSSs have proven to be efficient in performing their assigned tasks, which operate on the excitation system of generators. However, PSSs may unfavorably have an effect on the voltage profile, may result in a leading power factor, and may be unable to control oscillations caused by large disturbances such as three phase faults which may occur at the generator terminals $[2,3]$. Some of these were due to the limited capability of PSS, in damping only local and not inter-area modes of electro-mechanical oscillations [4].

Recently, the fast progress in the field of power electronics has opened new opportunities for the application of the FACTS devices as one of the most useful ways to improve power system operation controllability and solving various power system steady state control problems, such as voltage regulation, transfer capability enhancement, power flow control and damping of power system oscillations [3, 5-6].

SSSC and STATCOM are two important members of FACTS family, which can be installed in series and parallel in the transmission lines. Although the main function of SSSC and STATCOM is to control the power flow but they can be used, as an impressive device, to

Received: April $20^{\text {th }}, 2015$. Accepted: September $24^{\text {th }}, 2016$

DOI: 10.15676/ijeei.2016.8.3.15 
control power system oscillations. Recently, optimization methods such as genetic algorithm (GA) and particle swarm optimization (PSO), are used for obtaining parameters of controlling techniques. The application of SSSC and STATCOM based controllers for power oscillations damping and dynamical stability improvement can be found in several references [7-12].

A proper controller is capable of better controlling nonlinear system with fast changing dynamics, like a power system, since the dynamics of a power system are successively identified by a model. The benefits of on-line adaptive controllers over conventional controllers are that they are able to adapt to changes in system operating conditions automatically, different from conventional controllers whose efficiency and productivity is degraded by such changes and need re-tuning in order to provide the desired efficiency [13].

Some researchers used fuzzy logic based damping control strategy for TCSC, UPFC and SVC in a multi-machine power system [14] and [15]. Besides, the initial parameters adjustment of this type of controller requires some trial and error. Khon and Lo [16] used a fuzzy damping controller designed by micro Genetic Algorithm (GA) for TCSC and UPFC to increase power system dynamical stability. Abido has used the PSO technique to design a controller and this approach not only is an off-line procedure, but also relies greatly on the selection of the primary situations of control systems [17].

The COA algorithm is a new and very strong method for optimization and has emerged as a useful tool for engineering optimization. So it is used in multiple applications, such as PID controller designing [18] or optimal placement and sizing of distributed generations (DG) [19].

This paper presents use of COA for controller parameter designing of two FACTS-based devices as well as a comparative study on the effects of COA based SSSC and STATCOM controllers on power system electromechanical oscillations damping. The optimal selection of the output feedback parameters for both SSSC and STATCOM controllers is converted to an optimization problem, which is solved by recently developed COA method. In this study, a single machine infinite bus (SMIB) system integrated with both STATCOM and SSSC controllers is used. The effectiveness and robustness of the proposed COA based SSSC and STATCOM controllers, are demonstrated through time-domain simulation and some performance indices are used to study the damping of low frequency oscillations under various loading conditions and a large disturbance.

\section{Proposed COA method}

The COA is a new heuristic algorithm for global optimization searches. This optimization algorithm is inspired by the life of a bird family, called Cuckoo. Particular lifestyle of these birds and their specifications in egg laying and breeding has been the basic motivation for expansion of this new evolutionary optimization algorithm. COA similar to other heuristic algorithms such as PSO, GA, imperialist competitive algorithm (ICA), etc, starts with an initial population. The cuckoo population, in different societies, is divided into two types, mature cuckoos and eggs. These initial cuckoos grow and they have some eggs to lay in some host birds' nests. Among them, each cuckoo starts laying eggs randomly in some other host birds' nests within her egg laying radius (ELR) [18]. Some of these eggs, which are more like to the host bird's eggs have the opportunity to grow up and become a mature cuckoo. Other eggs are detected by host birds and are destroyed. The grown eggs disclose the suitability of the nests in that area. The more eggs survive in an area, the more benefit is gained in that area. So the location in which more eggs survive will be the term that COA is going to optimize. Then they immigrate into this best habitat. Each cuckoo only flies $\lambda \%$ of all distance toward final destination (goal habitat) and also has a deviation of $\phi$ radians. The parameters of $\lambda$ and $\phi$ help cuckoos to search much more positions in the environment. For each cuckoo, $\lambda$ and $\phi$ are defined as follows:

$$
\lambda \sim U(0,1), \phi \sim U(-\omega, \omega)
$$


where $\lambda \sim U(0,1)$ means that $\lambda$ is a random number that is uniformly distributed between 0 and 1. $\omega$ is a parameter that determines the maximum deviation from the goal habitat. When all cuckoos immigrated toward final destination and new habitats were specified, each mature cuckoo is given some eggs. Then considering the number of eggs allocated to each bird, an ELR is calculated for each cuckoo. Then new egg laying process restarts [18].

\section{Power system model}

A. Power system model with the SSSC

Figure 1 shows a SMIB power system equipped with a SSSC. The SSSC consists of a boosting transformer with a leakage reactance $X_{S C T}$, a gate turn off-based voltage source converter $\left(V_{I N V}\right)$, and a DC capacitor $\left(C_{D C}\right)$. The two input control signals to the SSSC are $m$ and $\Psi$. Signal $m$ is the amplitude modulation ratio of the pulse width modulation (PWM) based VSC. Also, signal $\Psi$ is the phase of the injected voltage and is kept in quadrature with the line current (inverter losses are ignored). The test system data is given in the appendix.

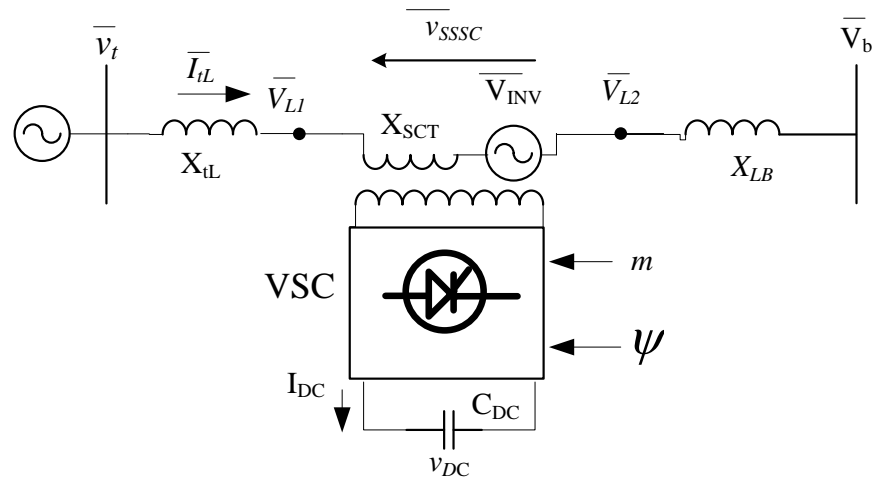

Figure 1. SSSC installed on a SMIB system

The dynamic model of the SSSC can be modeled as [8]:

$$
\begin{aligned}
& \bar{I}_{t L}=I_{t L d}+j I_{t L q}=I_{T L} \angle L \varphi \\
& \bar{V}_{I N V}=m k V_{D C}(\cos \Psi+j \sin \Psi) \\
& \Psi=\varphi \pm 90 \\
& \dot{V}_{D C}=\frac{d V_{D C}}{d t}=\frac{I_{D C}}{C_{D C}} \\
& \dot{V}_{D C}=\frac{m k}{C_{D C}}\left(I_{t L d} \cos \Psi+I_{t L q} \sin \Psi\right)
\end{aligned}
$$

where, $k$ is the ratio between $\mathrm{AC}$ and DC voltages and is dependent on the inverter structure. The non-linear dynamic model of the power system in Figure 1 is [8]:

$$
\begin{aligned}
& \dot{\delta}=\omega_{b} \omega \\
& \dot{\omega}=\left(P_{m}-P_{e}-D \omega\right) / M \\
& \dot{E}_{q}^{\prime}=\left(-E_{q}+E_{f d}\right) / T_{d o}^{\prime} \\
& \dot{E}_{f d}=-\frac{1}{T_{A}} E_{f d}+\frac{K_{A}}{T_{A}}\left(V_{t o}-V_{t}\right)
\end{aligned}
$$

where,

$$
\begin{aligned}
& P_{e}=E_{q}^{\prime} I_{t L q}+\left(X_{q}-X_{d}^{\prime}\right) I_{t L d} I_{t L q} \\
& E_{q}=E_{q}^{\prime}+\left(X_{d}-X_{d}^{\prime}\right) I_{t L d} \\
& V_{t}=\sqrt{\left(E_{q}^{\prime}-X_{d}^{\prime} I_{t L d}\right)^{2}+\left(X_{q} I_{t L q}\right)^{2}}
\end{aligned}
$$


A linear dynamic model is obtained by linearizing the nonlinear model round an operating condition. By linearization using Eq. (2)-(9), the linearized model of power system can be found as follows [8]:

$$
\begin{aligned}
& \Delta \dot{\delta}=\omega_{b} \Delta \omega \\
& \Delta \dot{\omega}=\left(-\Delta P_{e}-D \Delta \omega\right) / M \\
& \Delta \dot{E}_{q}^{\prime}=\left(-\Delta E_{q}+\Delta E_{f d}\right) / T_{d o}^{\prime} \\
& \Delta \dot{E}_{f d}=-\frac{1}{T_{A}} \Delta E_{f d}-\frac{K_{A}}{T_{A}} \Delta V_{t} \\
& \Delta \dot{V}_{D C}=K^{\prime}{ }_{7} \Delta \delta+K^{\prime}{ }_{8} \Delta E_{q}^{\prime}+K^{\prime}{ }_{9} \Delta V_{D C}+K^{\prime}{ }_{d m} \Delta m+K^{\prime}{ }_{d \Psi} \Delta \Psi
\end{aligned}
$$

where,

$$
\begin{aligned}
& \Delta P_{e}=K^{\prime}{ }_{1} \Delta \delta+K^{\prime}{ }_{2} \Delta E_{q}^{\prime}+K^{\prime}{ }_{p D C} \Delta V_{D C}+K^{\prime}{ }_{p m} \Delta m+K^{\prime}{ }_{p \Psi} \Delta \Psi \\
& \Delta E_{q}=K^{\prime}{ }_{4} \Delta \delta+K^{\prime}{ }_{3} \Delta E_{q}^{\prime}+K^{\prime}{ }_{q D C} \Delta V_{D C}+K^{\prime}{ }_{q m} \Delta m+K^{\prime}{ }_{q \Psi} \Delta \Psi \\
& \Delta V_{t}=K^{\prime}{ }_{5} \Delta \delta+K^{\prime}{ }_{6} \Delta E_{q}^{\prime}+K^{\prime}{ }_{v D C} \Delta V_{D C}+K^{\prime}{ }_{v m} \Delta m+K^{\prime}{ }_{v \Psi} \Delta \Psi
\end{aligned}
$$

$K_{1}^{\prime}, K_{2}^{\prime} \ldots K_{9}^{\prime}, K_{p u}^{\prime}, K_{q u}^{\prime}$ and $K_{v u}^{\prime}$ are linearization constants and are dependent on system parameters and the operating condition. The state space model of power system is given by:

$$
\dot{x}=A x+B u
$$

where the state vector $x$, control vector $u, A$ and $B$ are:

$$
\begin{aligned}
& x=\left[\begin{array}{lllll}
\Delta \delta & \Delta \omega & \Delta E^{\prime}{ }_{q} & \Delta E_{f d} & \Delta V_{D C}
\end{array}\right]^{T} \\
& u=\left[\begin{array}{ll}
\Delta m & \Delta \Psi
\end{array}\right]^{T} \\
& A=\left[\begin{array}{ccccc}
0 & w_{b} & 0 & 0 & 0 \\
-\frac{K_{1}^{\prime}}{M} & -\frac{D}{M} & -\frac{K^{\prime}{ }_{2}}{M} & 0 & -\frac{K^{\prime}{ }_{p D C}}{M} \\
-\frac{K^{\prime}{ }_{4}}{T^{\prime}{ }_{d o}} & 0 & -\frac{K^{\prime}{ }_{3}}{T^{\prime}{ }_{d o}} & \frac{1}{T^{\prime}{ }_{d o}} & -\frac{K^{\prime}{ }_{q D C}}{T^{\prime}{ }_{d o}} \\
-\frac{K_{A} K^{\prime}{ }_{5}}{T_{A}} & 0 & -\frac{K_{A} K_{6}^{\prime}}{T_{A}} & -\frac{1}{T_{A}} & -\frac{K_{A} K^{\prime}{ }_{v D C}}{T_{A}} \\
K^{\prime}{ }_{7} & 0 & K^{\prime}{ }_{8} & 0 & K^{\prime}{ }_{9}
\end{array}\right] \\
& B=\left[\begin{array}{cc}
0 & 0 \\
-\frac{K_{p m}^{\prime}}{M} & -\frac{K_{p \Psi}^{\prime}}{M} \\
-\frac{K_{q m}^{\prime}}{T_{d o}^{\prime}} & -\frac{K_{q \Psi}^{\prime}}{T^{\prime^{\prime}}{ }_{d o}} \\
-\frac{K_{A} K_{v m}^{\prime}}{T_{A}} & -\frac{K_{A} K^{\prime}{ }_{v \Psi}}{T_{A}} \\
K_{d m}^{\prime} & K_{d \Psi}^{\prime}
\end{array}\right]
\end{aligned}
$$

Figure 2 shows the block diagram of the linearized dynamic model of the test system with SSSC. 


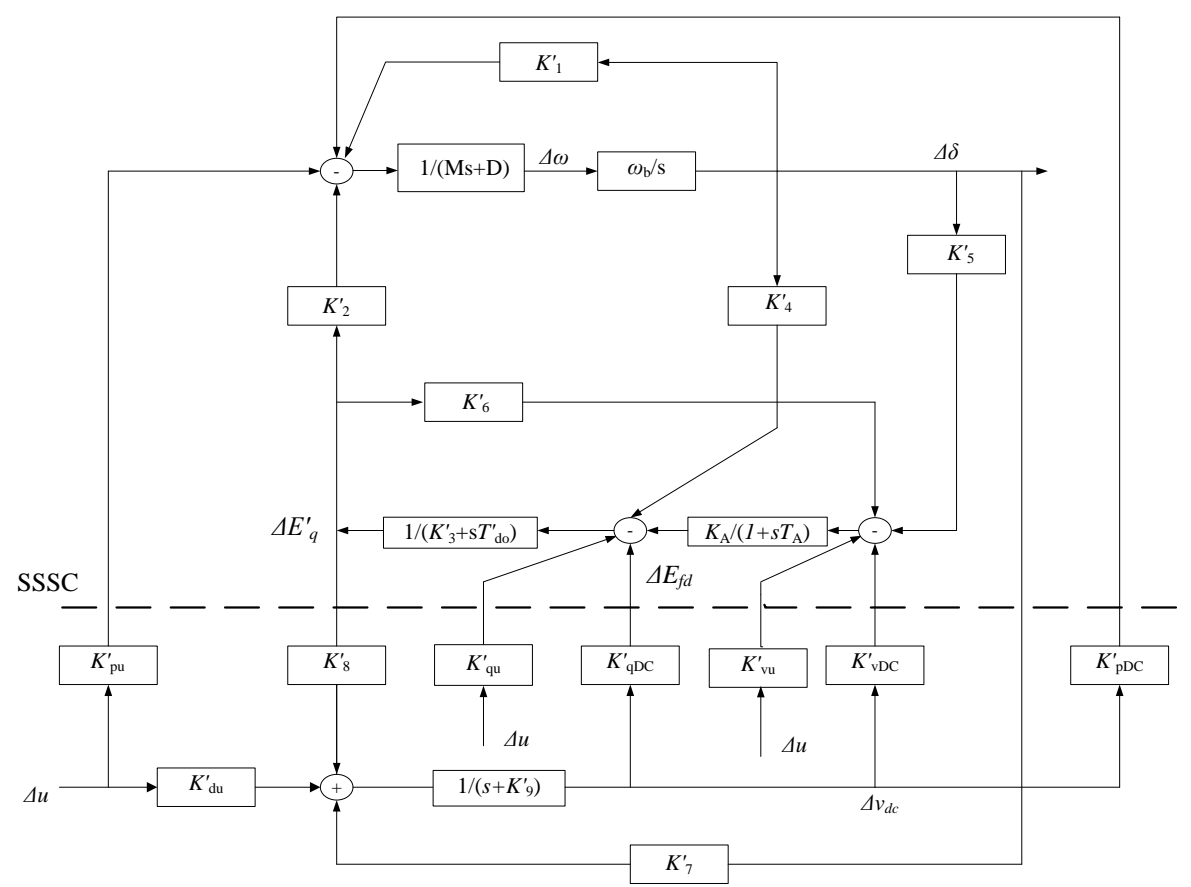

Figure 2. Modified Phillips-Heffron model of a SMIB system with SSSC.

\section{B. Power system model with the STATCOM}

A SMIB power system installed with a STATCOM shown in Figure 3 is widely used for studies of power system oscillations. It is adopted in this paper to demonstrate the proposed method. The system consists of a step down transformer with a leakage reactance $X_{S D T}$, a gate turn off-based voltage source converter, and a DC capacitor [11].

The STATCOM has two input control signals, modulation index $m$ and phase $\Psi$. In order to investigate the effects of the STATCOM on increasing the damping of power system low frequency oscillations, its dynamic model is required. Park's transformation is applied and the resistance and transients of the transformer are neglected, and so, the dynamic relation between the capacitor voltage and current in the STATCOM circuit are expressed as [11]:

$$
\begin{aligned}
& \bar{I}_{L O}=I_{L O d}+j I_{L O q} \\
& \bar{V}_{O}=m k V_{D C}(\cos \Psi+j \sin \Psi) \\
& \dot{V}_{D C}=\frac{d V_{D C}}{d t}=\frac{I_{D C}}{C_{D C}} \\
& \dot{V}_{D C}=\frac{m k}{C_{D C}}\left(I_{L O d} \cos \Psi+I_{L O q} \sin \Psi\right)
\end{aligned}
$$

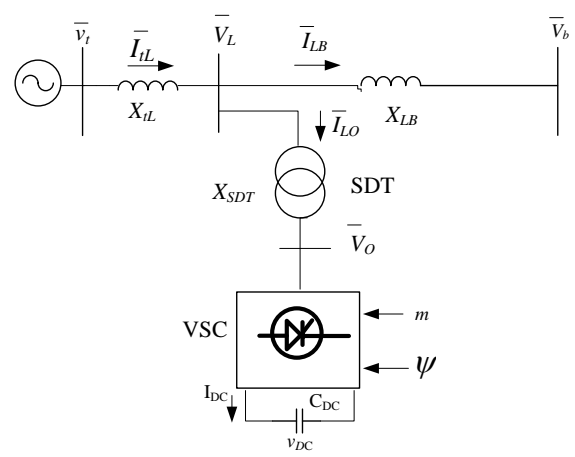

Figure 3. STATCOM installed on a SMIB system 
In the above equations, $k$ is the voltage ratio between the $\mathrm{AC}$ and $\mathrm{DC}$ sides and is dependent on the inverter structure. The nonlinear dynamic model of the presented power system with STATCOM in Figure 3 is [11]:

$$
\begin{aligned}
& \dot{\delta}=\omega_{b} \omega \\
& \dot{\omega}=\left(P_{m}-P_{e}-D \omega\right) / M \\
& \dot{E}_{q}^{\prime}=\left(-E_{q}+E_{f d}\right) / T_{d o}^{\prime} \\
& \dot{E}_{f d}=-\frac{1}{T_{A}} E_{f d}+\frac{K_{A}}{T_{A}}\left(V_{t o}-V_{t}\right)
\end{aligned}
$$

where,

$$
\begin{aligned}
& P_{e}=E_{q}^{\prime} I_{t L q}+\left(X_{q}-X_{d}^{\prime}\right) I_{t L d} I_{t L q} \\
& E_{q}=E_{q}^{\prime}+\left(X_{d}-X_{d}^{\prime}\right) I_{t L d} \\
& V_{t}=\sqrt{\left(E_{q}^{\prime}-X_{d}^{\prime} I_{t L d}\right)^{2}+\left(X_{q} I_{t L q}\right)^{2}}
\end{aligned}
$$

A linear dynamic model is obtained by linearizing the nonlinear model round an operating condition. By linearization using Eq. (16)-(23), the linearized model of power system is given as follows [11]:

$$
\begin{aligned}
& \Delta \dot{\delta}=\omega_{b} \Delta \omega \\
& \Delta \dot{\omega}=\left(-\Delta P_{e}-D \Delta \omega\right) / M \\
& \Delta \dot{E}_{q}^{\prime}=\left(-\Delta E_{q}+\Delta E_{f d}\right) / T_{d o}^{\prime} \\
& \Delta \dot{E}_{f d}=-\frac{1}{T_{A}} \Delta E_{f d}-\frac{K_{A}}{T_{A}} \Delta V_{t} \\
& \Delta \dot{V}_{D C}=K_{7} \Delta \delta+K_{8} \Delta E_{q}^{\prime}+K_{9} \Delta V_{D C}+K_{d m} \Delta m+K_{d \Psi} \Delta \Psi
\end{aligned}
$$

where,

$$
\begin{aligned}
& \Delta P_{e}=K_{1} \Delta \delta+K_{2} \Delta{E^{\prime}}_{q}+K_{p D C} \Delta V_{D C}+K_{p m} \Delta m+K_{p \Psi} \Delta \Psi \\
& \Delta E_{q}=K_{4} \Delta \delta+K_{3} \Delta{E^{\prime}}_{q}+K_{q D C} \Delta V_{D C}+K_{q m} \Delta m+K_{q \Psi} \Delta \Psi \\
& \Delta V_{t}=K_{5} \Delta \delta+K_{6} \Delta{E^{\prime}}_{q}+K_{v D C} \Delta V_{D C}+K_{v m} \Delta m+K_{v \Psi} \Delta \Psi
\end{aligned}
$$

$K_{1}, K_{2} \ldots K_{9}, K_{p u}, K_{q u}$ and $K_{v u}$ are linearization constants and are dependent on system parameters and the operating condition. The state space model of power system is given by:

$$
\dot{x}=A x+B u
$$

where the state vector $x$, control vector $u, A$ and $B$ are:

$$
\begin{aligned}
x & =\left[\begin{array}{lllll}
\Delta \delta & \Delta \omega & \Delta E^{\prime}{ }_{q} & \Delta E_{f d} & \Delta V_{D C}
\end{array}\right]^{T} \\
u & =\left[\begin{array}{lllll}
\Delta m & \Delta \Psi
\end{array}\right]^{T} \\
A & =\left[\begin{array}{ccccc}
0 & \omega_{b} & 0 & 0 & 0 \\
-\frac{K_{1}}{M} & -\frac{D}{M} & -\frac{K_{2}}{M} & 0 & -\frac{K_{p D C}}{M} \\
-\frac{K_{4}}{T_{d o}^{\prime}} & 0 & -\frac{K_{3}}{T^{\prime}{ }_{d o}} & \frac{1}{T^{\prime}{ }^{\prime} o} & -\frac{K_{q D C}}{T^{\prime}{ }_{d o}} \\
-\frac{K_{A} K_{5}}{T_{A}} & 0 & -\frac{K_{A} K_{6}}{T_{A}} & -\frac{1}{T_{A}} & -\frac{K_{A} K_{v D C}}{T_{A}} \\
K_{7} & 0 & K_{8} & 0 & K_{9}
\end{array}\right]
\end{aligned}
$$




$$
B=\left[\begin{array}{cc}
0 & 0 \\
-\frac{K_{p m}}{M} & -\frac{K_{p \Psi}}{M} \\
-\frac{K_{q m}}{T_{d o}^{\prime \prime}} & -\frac{K_{q \Psi}}{T^{\prime^{\prime}}} \\
-\frac{K_{A} K_{v m}}{T_{A}} & -\frac{K_{A} K_{v \Psi}}{T_{A}} \\
K_{d m} & K_{d \Psi}
\end{array}\right]
$$

Figure 4 shows the block diagram of the linearized dynamic model of the test system with STATCOM.

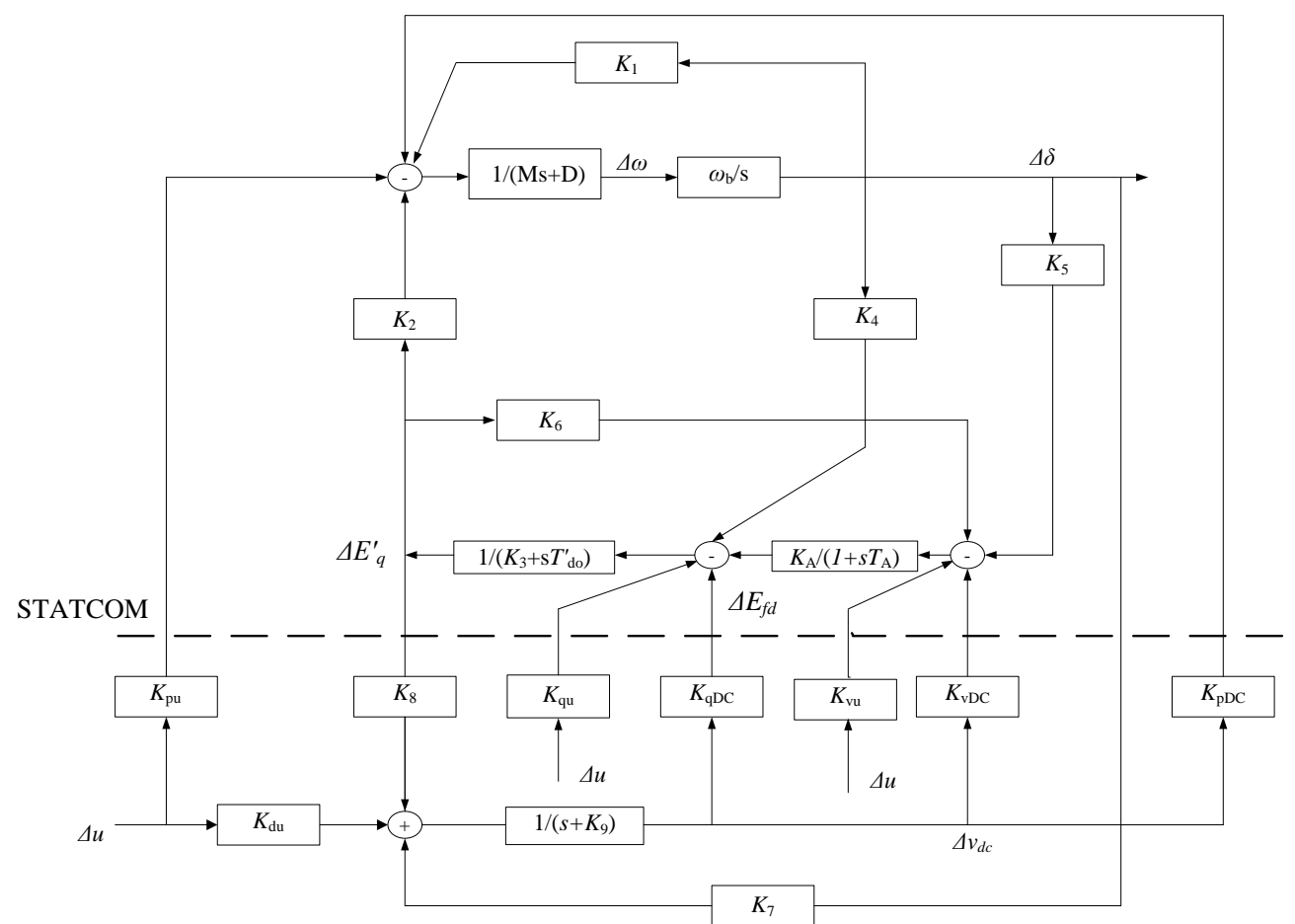

Figure 4. Modified Phillips-Heffron model of a SMIB system with STATCOM

\section{COA based SSSC and STATCOM damping controllers designing}

\section{A. SSSC and STATCOM based proposed controllers structure}

The SSSC and STATCOM damping controllers' structure is shown in Figure 5, where $u$ can be $m$ or $\Psi$. It comprises gain block, signal-washout block and lead-lag compensators [5].

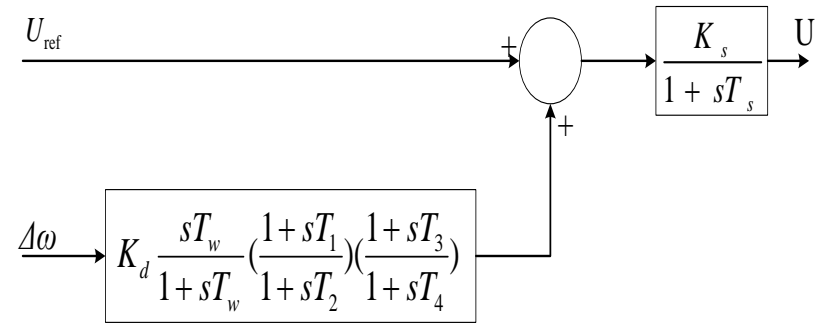

Figure 5. Lead-lag damping controller structure. 
Based on singular value decomposition (SVD) analysis in [20, 21] modulating $\Psi$ has an excellent capability in damping low frequency oscillations in comparison to other inputs of SSSC and STATCOM, thus in this paper, $\Psi$ is modulated in order to damping controller design.

\section{B. Objective function}

In the proposed COA method, parameters of the the SSSC and STATCOM controllers must be tuned optimally to improve overall system dynamic stability in a robust way under different operating conditions. For this reason, an eigenvalue based multi-objective function reflecting the combination of damping factor and damping ratio is considered as follows:

$$
J=\sum_{i=1}^{N p}\left(\sigma_{0}-\sigma_{i}\right)^{2}+a \sum_{i=1}^{N p}\left(\xi_{0}-\xi_{i}\right)^{2}
$$

where $\sigma_{i}$ and $\xi_{i}$ are the real part and the damping ratio of the $i$ th eigenvalue, respectively. The value of $\sigma_{0}$ determines the relative stability in terms of damping factor margin provided for constraining the placement of eigenvalues during the process of optimization and $\xi_{0}$ is the desired minimum damping ratio, which is to be achieved. The closed loop eigenvalues are placed in the region to the left of dashed line as shown in Figure 6.

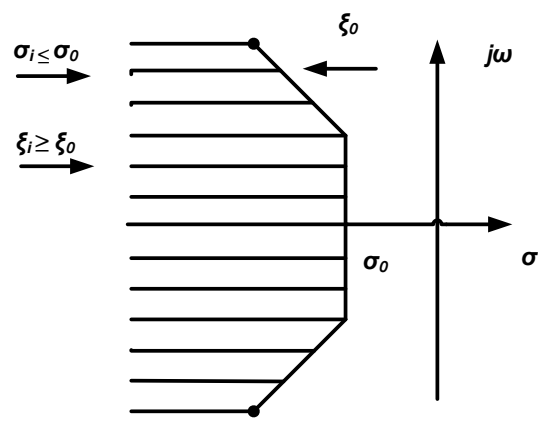

Figure 6. Region of eigenvalue location for multi-objective function

\section{Optimization problem}

In this study, it is aimed to minimize the proposed objective function $J$. The constraints are the stabilizer's parameter bounds. Therefore, the design problem can be formulated as the following optimization problem.

Minimize $J$

For the lead-lag controller subject to

$$
\begin{aligned}
& K_{\mathrm{d}}{ }^{\min } \leq K_{d} \leq K_{d}{ }^{\max } \\
& T_{1}{ }^{\min } \leq T_{1} \leq T_{1}{ }^{\max } \\
& T_{2}{ }^{\text {min }} \leq T_{2} \leq T_{2}{ }^{\text {max }} \\
& T_{3}{ }^{{ }^{\min }} \leq T_{3} \leq T_{3}{ }^{\text {max }} \\
& T_{4}{ }^{\min } \leq T_{4} \leq T_{4}{ }^{\max }
\end{aligned}
$$

Typical ranges of the five parameters of lead-lag controller are [-100, 100] for $K_{\mathrm{d}}$ and $[0.01$, 1.5] for $T_{1}, T_{2}, T_{3}$ and $T_{4}$.

\section{Simulation result}

\section{A. Application of COA method to the design process}

Figure7 shows the flowchart of the proposed COA method. Based on the linearized power system models with SSSC and STATCOM, the suggested approach employs COA algorithm to solve optimization problem and search for an optimal or near optimal set of controller 
parameters. The optimization of SSSC and STATCOM controller parameters is carried out by evaluating the multi-objective cost function as given in Eq. (30), for the lead-lag controller.

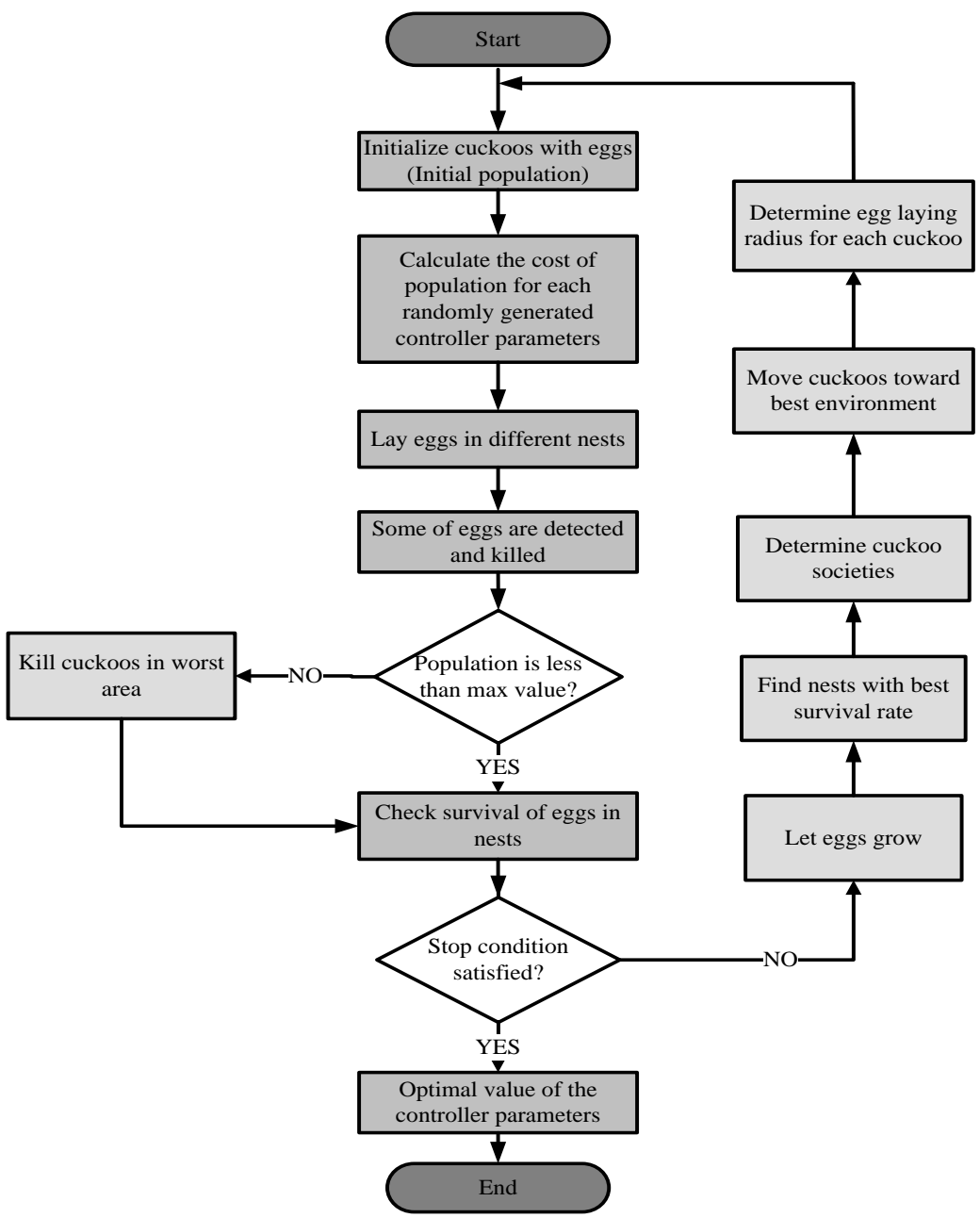

Figure 7. Flowchart of the proposed cuckoo optimization algorithm.

In this paper, the values of $\sigma_{0}, \xi_{0}$ and $a$ are taken as $-2,0.5$ and 10 , respectively. In order to acquire better performance of COA, proper parameters are given in Table 1 . Notice that the optimization process for the proposed controllers has been carried out with the system operating at nominal loading conditions given in Table 2. COA is run one and 20 times and the best solution based on the minimum cost function is selected. Table 3 shows the optimal controller parameters with one and average of 10 runs. It can be seen that COA performance in 20 times run is the same as in one time run. Figure 8 shows the cost of COA controller for the SSSC and STATCOM with the same objective function when the program is run once and 20 times. As it can be seen from this figure, for the same objective function, the cost value of COA based SSSC controller is less than STATCOM.

Eigenvalues and damping ratios of the electromechanical modes with COA method at 3 different loading conditions are given in Table 4. The results show that the COA-based SSSC controller acts better than the STATCOM controller and greatly improves the dynamic stability of the power system. 
Table 1. Cuckoo algorithm proper parameters

\begin{tabular}{|l|l|}
\hline initial population & 20 \\
\hline minimum and maximum number of eggs for each cuckoo & 2 and 4 \\
\hline number of clusters & 3 \\
\hline maximum number of cuckoos & 30 \\
\hline Iteration & 50 \\
\hline
\end{tabular}

Table 2. System loading conditions

\begin{tabular}{|l|l|l|}
\hline Loading Conditions & P (P.U.) & Q (P.U.) \\
\hline Case1 (Nominal) & 1 & 0.15 \\
\hline Case2 (Light) & 0.3 & 0.015 \\
\hline Case3 (Heavy) & 1.1 & 0.4 \\
\hline
\end{tabular}

Table 3. The optimal parameter settings of COA-based controller with one and average of 20 runs

\begin{tabular}{|l|c|c|c|c|c|c|c|}
\hline \multicolumn{2}{|c|}{ controller parameters } & $\mathrm{K}_{\mathrm{d}}$ & $\mathrm{T}_{1}$ & $\mathrm{~T}_{2}$ & $\mathrm{~T}_{3}$ & $\mathrm{~T}_{4}$ & Cost \\
\hline \multirow{3}{*}{ SSSC } & $\begin{array}{c}1 \text {-run } \\
\text { COA }\end{array}$ & 87.1141 & 1.5000 & 0.1834 & 0.3670 & 0.2095 & 1.8194 \\
\cline { 2 - 8 } & $\begin{array}{c}20 \text {-runs } \\
\text { COA }\end{array}$ & 100 & 0.0713 & 0.2132 & 1.4817 & 0.0100 & 1.7619 \\
\hline \multirow{3}{*}{ STATCOM } & $\begin{array}{c}1-\text { run } \\
\text { COA }\end{array}$ & -30.7534 & 0.0100 & 0.0440 & 0.0477 & 0.0413 & 5.8690 \\
\cline { 2 - 8 } & $\begin{array}{c}20 \text {-runs } \\
\text { COA }\end{array}$ & -32.7420 & 0.0211 & 0.0396 & 0.0103 & 0.0229 & 5.8424 \\
\hline
\end{tabular}

Table 4. Eigenvalues and damping ratios of the electromechanical modes of the system with designed COA based SSSC and STATCOM controllers

\begin{tabular}{|c|c|c|c|c|c|c|}
\hline $\begin{array}{c}\text { Loading } \\
\text { conditions }\end{array}$ & \multicolumn{2}{|c|}{ Case 1 } & \multicolumn{2}{c|}{ Case 2 } & \multicolumn{2}{c|}{ Case 3 } \\
\hline \multirow{2}{*}{ Devices } & Eigen-values & $\xi$ & Eigen-values & $\xi$ & Eigen-values & $\xi$ \\
\hline \multirow{5}{*}{ SSSC } & - & 0.9341 & - & 0.9732 & $-101.99 \pm \mathrm{j} 67.24$ & 0.8349 \\
& $97.8351 \pm \mathrm{j} 37.3777$ & 0.5043 & $28.0567 \pm \mathrm{j} 6.6324$ & 0.7171 & $-3.06 \pm \mathrm{j} 1.14$ & 0.9371 \\
& $-4.0291 \pm \mathrm{j} 6.8998$ & 0.4629 & $-5.8923 \pm \mathrm{j} 5.7263$ & 0.4619 & $-0.83 \pm \mathrm{j} 2.74$ & 0.2899 \\
& $-3.1441 \pm \mathrm{j} 6.0207$ & & $-1.5312 \pm \mathrm{j} 2.9405$ & & -16.1400 & \\
& -28.8104 & & -73.2125 & & -0.7700 & \\
& -7.7471 & & -1.4692 & & -0.2143 & \\
& -0.6756 & & -0.0012 & & & \\
& $-4.5568 \pm \mathrm{j} 5.9248$ & 0.6096 & $-94.39 \pm \mathrm{j} 9.72$ & 0.9947 & - & 0.7244 \\
& $-0.4432 \pm \mathrm{j} 2.1809$ & 0.1991 & $-0.18 \pm \mathrm{j} 2.62$ & 0.0685 & $6.9486 \pm \mathrm{j} 6.6125$ & 0.0755 \\
& -90.4536 & & -109.7600 & & $-0.1916 \pm \mathrm{j}$ & \\
& -43.5754 & & -4.6200 & & 2.5319 & \\
STATCOM & -29.1703 & & -1.5600 & & -89.7437 & \\
& -16.5030 & & -0.1992 & & -43.5782 & \\
& -0.1976 & & -0.0140 & & -29.2458 & \\
& & & & & -16.6314 & \\
& & & & & -0.9503 & \\
\hline
\end{tabular}




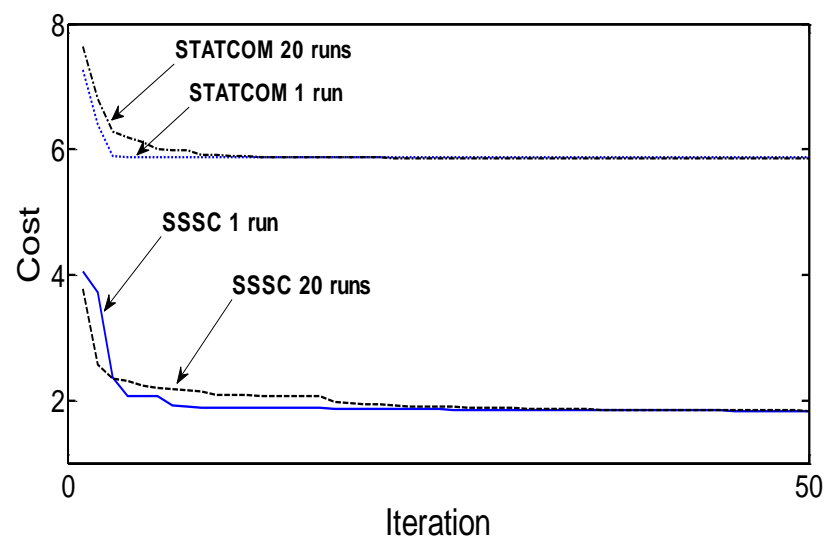

Figure 8. The convergence characteristics of optimal COA-based SSSC and STATCOM controller designing.

\section{B. Time domain simulation}

The performance of the suggested COA method for the SSSC and STATCOM during transient conditions is verified by applying $10 \%$ increase in mechanical power input at $\mathrm{t}=1 \mathrm{~s}$. The system responses with SSSC and STATCOM controllers to this disturbance under 3 different loading conditions for speed deviation, rotor angle deviation and power deviation with $\Psi$ based controller are shown in Figs. 9-11. Simulation results clearly illustrate abilities of the SSSC and the STATCOM in low-frequency oscillation damping, while showing that the SSSC has better performance in damping low-frequency oscillations and stabilizes the system quickly in comparison to the STATCOM. The results obtained, confirms the result of the reference [22].

\section{Conclusion}

This paper presented a COA-based power oscillation damping controller in which the controller was installed on a SSSC or a STATCOM. The stabilizer design problem was formulated as an optimization problem, which was solved by COA as a new and strong optimization method. The proposed stabilizers were applied and tested on power system under major disturbance and different loading conditions. It is clear from the simulation results that both FACTS devices improve the system stability. Furthermore, the SSSC-based stabilizer is more effective than STATCOM-based stabilizer in damping of power system oscillations. The results obtained confirmed the effectiveness of the COA method for controller parameter optimization.

\section{Appendix}

The nominal parameters and operating condition of the case study system are listed in Table 5 .

Table 5. System parameters

\begin{tabular}{|l|c|c|c|}
\hline \multirow{2}{*}{ Generator } & $\begin{array}{c}M=8.0 \mathrm{MJ} / \mathrm{MVA} \\
D=0.0 \\
T^{\prime}{ }_{d o}=5.044 \mathrm{~s}\end{array}$ & $\begin{array}{c}f=60 \mathrm{~Hz} \\
V=1 \mathrm{pu} \\
x_{d}=1.0 \mathrm{pu}\end{array}$ & $\begin{array}{c}x_{q}=0.6 \mathrm{pu} \\
x^{\prime}{ }_{d}=0.3 \mathrm{pu}\end{array}$ \\
\hline Excitation System & $K_{A}=120$ & $T_{A}=0.05 \mathrm{~s}$ & \\
\hline Transmission Line & $X_{L L}=0.15 \mathrm{pu}$ & $X_{L B}=0.6 \mathrm{pu}$ & \\
\hline \multirow{2}{*}{ SSSC } & $C_{D C}=0.25$ & $K_{S}=1.2$ & $T_{w}=0.01 \mathrm{~s}$ \\
& $V_{D C}=1 \mathrm{pu}$ & $T_{S}=0.05 \mathrm{~s}$ & $X_{S C T}=0.15 \mathrm{pu}$ \\
\hline \multirow{2}{*}{ STATCOM } & $C_{D C}=1$ & $K_{S}=1.2$ & $T_{w}=0.01 \mathrm{~s}$ \\
& $V_{D C}=2 \mathrm{pu}$ & $T_{S}=0.05 \mathrm{~s}$ & $X_{S C T}=0.15 \mathrm{pu}$ \\
\hline
\end{tabular}


(a)

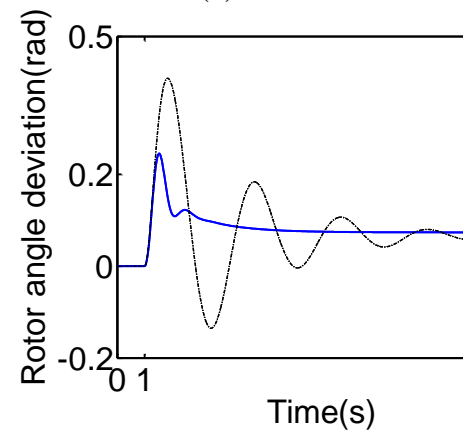

(b)

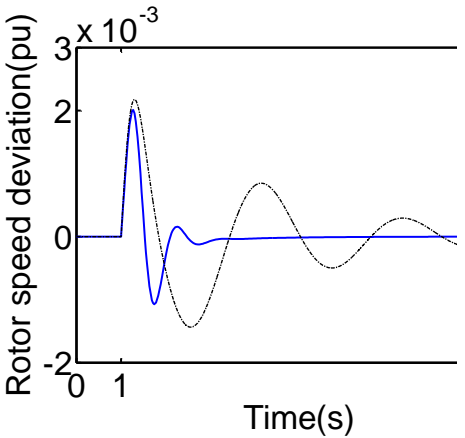

(c)

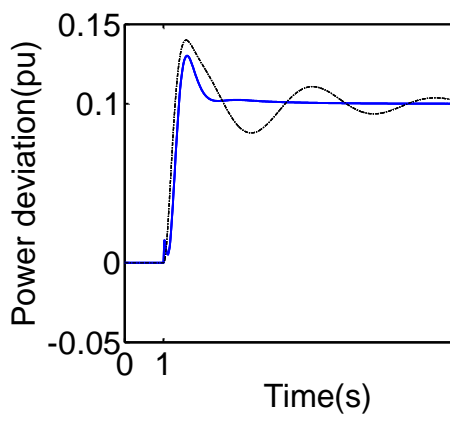

Figure 9. Dynamic responses for (a) $\Delta \delta$, (b) $\Delta \omega$ and (c) $\Delta \mathrm{P}_{\mathrm{e}}$ with $\Psi$ controller in Case 1 loading condition; solid (proposed COA-based SSSC controller) and dash-dotted (proposed COAbased STATCOM controller).

(a)

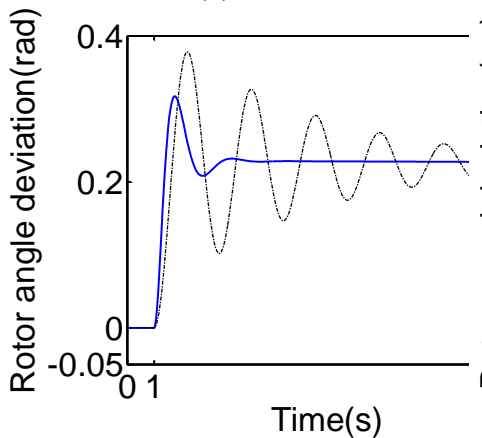

(b)

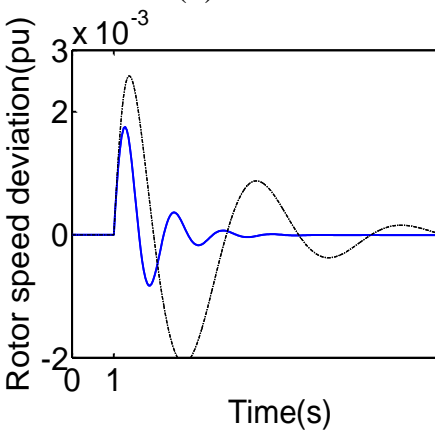

(c)

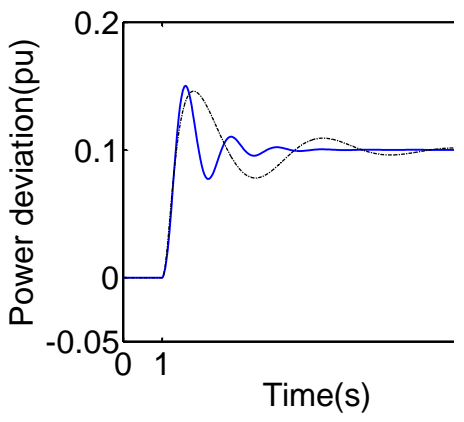

Figure 10. Dynamic responses for (a) $\Delta \delta$, (b) $\Delta \omega$ and (c) $\Delta \mathrm{P}_{\mathrm{e}}$ with $\Psi$ controller in Case 2 loading condition; solid (proposed COA-based SSSC controller) and dash-dotted (proposed COA-based STATCOM controller).

(a)

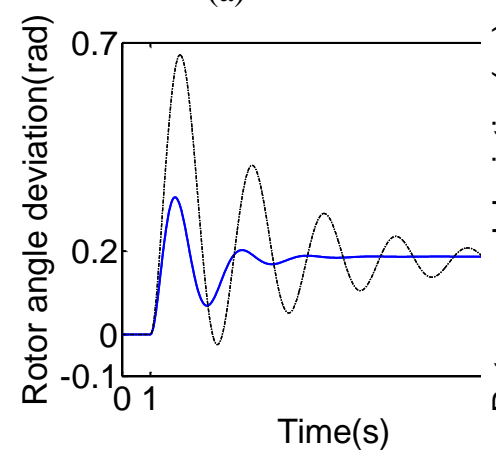

(b)

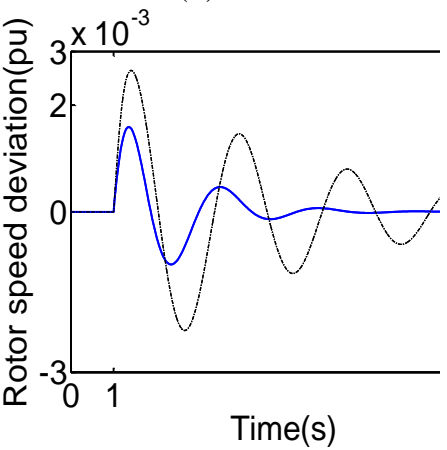

(c)

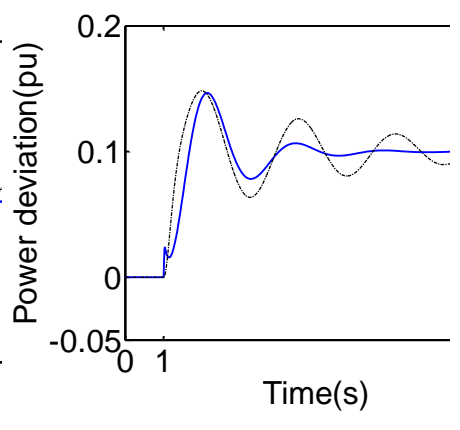

Figure 11. Dynamic responses for (a) $\Delta \delta$, (b) $\Delta \omega$ and (c) $\Delta \mathrm{P}_{\mathrm{e}}$ with $\Psi$ controller in Case 3 loading condition; solid (proposed COA-based SSSC controller) and dash-dotted (proposed COA-based STATCOM controller). 


\section{References}

[1]. P. Kundur, "Power System Stability and Control", New York, McGraw-Hill, 1994.

[2]. P.M. Anderson, A.A. Fouad, "Power System Control and Stability, Ames", Iowa State University Press, 1977.

[3]. A.T. Al-Awami, Y.L. Abdel-Magid, M.A. Abido, "A particle-swarm-based approach of power system stability enhancement with unified power flow controller", Electrical Power and Energy System, Vol. 29, pp. 251-259, 2007.

[4]. A.J.F. Keri, A.S. Mehraban, X. Lombard, A. Eiriachy, A.A. Edris, "Unified power flow controller (UPFC): modeling and analysis", IEEE Transactions on Power Delivery, Vol. 14, pp. 648-654, 1999.

[5]. H. Shayeghi, H.A. Shayanfar, S. Jalilzadeh, A. Safari, "A PSO based unified power flow controller for damping of power system oscillations", Energy Conversion and Management, Vol. 50, pp. 2583-2592, 2009.

[6]. M. R. Banaei. B. Mohammadzadeh. R. Reza.Ahrabi "Damping of low frequency electromechanical oscillations using UPFC based on cuckoo optimization algorithm". International Journal on Electrical Engineering and Informatics, Vol. 6, No. 4, 2014.

[7]. Gyugyi, L, "Dynamic Compensation of AC Transmission Line by Solid State Synchronous Voltage sources", IEEE Transactions on Power Delivery, Vol. 9, pp. 904911,1994.

[8]. H.F. Wang, "Design of SSSC damping controller to improve power system oscillation stability", IEEE Africon, Vol. 1, pp. 495-500, 1999.

[9]. B. Mohammadzadeh. R. Gholizadeh-Roshanagh and S. Najafi Ravadanegh "Optimal designing of SSSC based supplementary controller for LFO damping of power system using COA", ECTI Transactions on Electrical Eng., Electronics, and Communications, Vol. 12, No. 2, pp. 64-72, 2014.

[10]. S. Panda, N.P. Padhy, "A PSO-based SSSC controller for improvement of transient stability Performance”, International Journal of Intelligent Technology, Vol. 2, pp. 28-35, 2007.

[11]. H.F. Wang, "Phillips-Heffron model of power systems installed with STATCOM and applications", IEE Proceedings Generation, Transmission and Distribution, Vol. 146, pp. 521-527, 1999.

[12]. K.R. Padiyar, N. Prabhu, "Design and performance evaluation of sub synchronous damping controller with STATCOM", IEEE Transactions on Power Delivery, Vol. 21, pp.1398-1405, 2006.

[13]. A. Kazemi, M. Ladjevardi, M.A.S. Masoum, "Optimal Selection of SSSC Based Damping Controller Parameters for Improving Power System Dynamic Stability Using Genetic Algorithm", Iranian Journal of Science \& Technology, Transaction B, Engineering, Vol. 29, No. B1, 2005.

[14]. M.H. Etesami, N. Farokhnia, S.H. Fathi, "A method based on imperialist competitive algorithm (ICA), aiming to mitigate harmonics in multilevel inverters", 2nd Power Electronics, Drive Systems and Technologies Conference, pp. 32-37, 2011.

[15]. J. Kennedy, R. Eberhart, "Particle swarm optimization", Proceeding of IEEE International Conference on Neural Networks 1995;4:1942-8.

[16]. I. Tsoulos, D. Gavrilis, E. Glavas, "Neural network construction and training using grammatical evolution", Science Direct Neuro computing Journal, Vol.72, Issues 1-3, December 2008, pp. 269-277.

[17]. R. Eberhart, J. Kennedy, "A new optimizer using particle swarm theory”, In: Proceeding of Sixth International Symposium on Micro Machine Human Science, vol. 4-6 October, 1995, p. 39-43.

[18]. R. Rajabioun, "Cuckoo optimization algorithm”, Applied Soft Computing, Vol. 11, pp. 5508-5518, 2011. 
[19]. M. Mokhtarifard, R. Noroozian, S. Molaei, "Determining the optimal placement and capacity of DG in intelligent distribution networks under uncertainty demands by COA", 2nd Iranian Conference on Smart Grids (ICSG), 2012.

[20]. M.A. Abido, "Analysis and assessment of STATCOM-based damping stabilizers for power system stability enhancement", Electric Power System Research, Vol. 73, pp. 177$185,2005$.

[21]. A. Ajami, M. Armaghan, "Application of multi-objective PSO algorithm for power system stability enhancement by means of SSSC", International Journal of Computer and Electrical Engineering, Vol. 2, pp. 838-845, 2010.

[22]. A. Ajami, M. Armaghan, "A comparative study in power oscillation damping by STATCOM and SSSC based on the multi-objective PSO algorithm", Turkish Journal of Electrical Engineering \& Computer Sciences, Vol. 21, pp. 213-224, 2013.

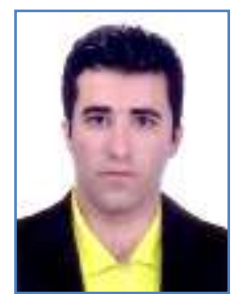

Behrouz Mohammadzadeh obtained his B.Sc. degree (2010) from Islamic Azad University of Ardabil, Ardabil, Iran and his M.Sc. degree (2014) from Azarbaijan Shahid Madani University (ASMU), Tabriz, Iran, both in Electrical Power Engineering. He is now a Ph.D. student of Electrical Power Engineering at ASMU. He is a member of Smart Distribution Grid Research Lab, E.E. Deprt, Azarbaijan Shahid Madani University, Tabriz, Iran. He is also a member of Young and Elite Researchers Club, Islamic Azad University. His research interests include evolutionary algorithms, planning and reliability assessment of power systems and operation of Micro-grids.

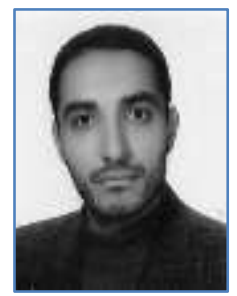

Reza Gholizadeh Roshanagh received from Azarbaijan Shahid Madani University (ASMU), Iran, the M.Sc. and Ph.D. degrees in Electrical Eng.in 2011 and 2016, respectively. Currently, he is a researcher in the Smart Distribution Grid Research Laboratory at the Azarbaijan Shahid Madani University. His major fields of interest include smart grid, distribution system planning, optimization algorithms applications in power systems, dc networks, and power system dynamics, stability, and control.

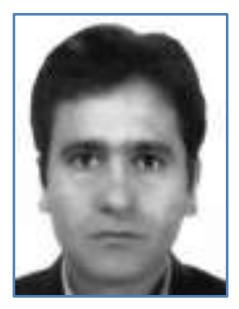

Sajad Najafi Ravadanegh was born in Iran, in 1976. He received the B.Sc. degree from the University of Tabriz, Tabriz, Iran, and the M.Sc. and Ph.D. degrees from the Amirkabir University of Technology, Tehran, Iran, in 2001, 2003, and 2009, respectively, all in electrical engineering. He is currently an Associate Professor with the Electrical Engineering Department, Azarbaijan Shahid Madani University (ASMU), Tabriz, where he is responsible for the Smart Distribution Grid Research Laboratory. His current research interests include smart distribution networks and microgrids' optimal operation and planning, power system stability and control, power system controlled islanding, optimization algorithms applications in power systems, nonlinear dynamic, and chaos. He has authored/coauthored over 60 technical papers.

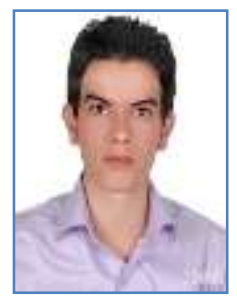

Seyed Reza Seyednouri was born in Parsabad, Ardabil, Iran in 1989. He received the B.S. and M.S.E. degrees in power Electrical Engineering from Islamic Azad University of Ardabil in 2011 and 2015, respectively. His research interests include renewable energy systems and penetration of photovoltaic generation in electrical distribution system. He is a member of Young researchers and elite club of Islamic Azad University. 